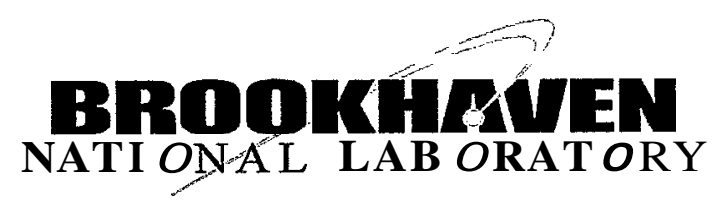

BNL-73493-2005-CP

\title{
Optimization of the Phase Advance between RHIC Interaction Points
}

\author{
R. Tomás, W. Fischer \\ Presented at the Particle Accelerator Conference(PAC'05) \\ Knoxville, Tennessee \\ May 16-20, 2005
}

Collider-Accelerator Department

Brookhaven National Laboratory

P.O. Box 5000

Upton, NY 11973-5000

www.bnl.gov

Managed by

Brookhaven Science Associates, LLC

for the United States Department of Energy under

Contract No. DE-AC02-98CH10886

This is a preprint of a paper intended for publication in a journal or proceedings. Since changes may be made before publication, this preprint is made availablewith the understandingthat it will not be cited or reproduced without the permission of the author. 


\section{DISCLAIMER}

This report was prepared as an account of work sponsored by an agency of the United States Government. Neither the United States Government nor any agency thereof, nor any of their employees, nor any of their contractors, subcontractors, or their employees, makes any warranty, express or implied, or assumes any legal liability or responsibility for the accuracy, completeness, or any third party's use or the results of such use of any information, apparatus, product, or process disclosed, or represents that its use would not infringe privately owned rights. Reference herein to any specific commercial product, process, or service by trade name, trademark, manufacturer, or otherwise, does not necessarily constitute or imply its endorsement, recommendation, or favoring by the United States Government or any agency thereof or its contractors or subcontractors. The views and opinions of authors expressed herein do not necessarily state or reflect those of the United States Government or any agency thereof.

FOR UNCLASSIFIED, UNLIMITED STIPRODUCTS

Available electronically at:

OSTI:

http://www.osti.gov/bridge

Available for a processing fee to U.S. Department of Energy and its contractors, in paper from:

US. Department of Energy

Office of Scientificand Technical Information

P.O. Box 62

Oak Ridge, TN 37831

Phone: (865) 576-8401

Facsimile: (865) 576-5728

E-mail: reports@adonis.osti.gov

National Technical Information Service (NTIS):

Available for sale to the public from:

US. Department of Commerce

National Technical Information Service

5285 Port Royal Road

Springfield, VA 22131

Phone: (800) 553-6847

Facsimile: (703) 605-6900

Online ordering: http://www.ntis.gov/ordering.htm

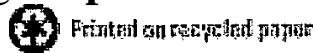




\title{
Optimization of the phase advance between RHIC interaction points*
}

\author{
R. Tomás, CELLS, Barcelona, Spain \\ W. Fischer, Brookhaven National Laboratory, Upton, NY 11973, USA
}

\section{Abstrast}

We consider a scenario of having two identical lnteraction Points (IPs) in the Relertivistic Heavy Ion Collider (RHC). The strengths of beati-bean resonattees strongly depend on the phase advance between these two TPs and therefore certein phase advances could improve beam lifen

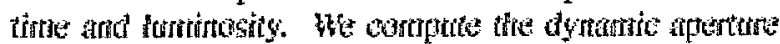
(DA) as function of the phase ad vance between these IT; to find the optimum settings. The beans beam intcraction is treated in the weak-strong approximation and a non-linear model of lle lattice is ased. For the current RHIC proton working point $(0.69,0.685)$ [ [ ] the dusign lattice is found to have the optimum phase advance. However this is not the case for other working points.

\section{INTRODUCTION}

The beam-beam interaction is a severe limit for the RHIC proton-proton luminosity. A 50\% emittance growth has been observed after $\mathbf{2}$ hours of beam collisions with a hunch intensity of $1.7 \times 10^{11}$ protons (see Fig. 1). The leminosity lifetime could in plineiple be inproved by reducing the strenght of the relevant ham-beam resonances. In this work we focus an the horizontal end yertical phase

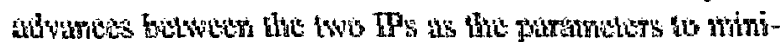
mize fesonatice strengths. Assuning two identical interaction points the beam bem interaction driwes the resonance $(j, h)$ wilh a stremgth given by

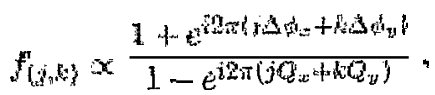

where $\phi_{x, y}$ are the horizontal and vertical phase advances and $Q_{x, y}$ are the horizontal and vertical tunes. From Eq. (1) one can deduce that for given tunes:

- The strength is maximumif

$$
j \Delta \phi_{x}+k \Delta \phi_{y}=\mathrm{N}, \quad \mathrm{N} \text { any integer }
$$

- The strength is zero if

$$
j \Delta \phi_{x}+k \Delta \phi_{y}=N / 2, \quad N \text { odd integer }
$$

The above equations predict lines in the horizontal and vertical phase advance plane where the resonances are either maximum or zero, thus rendering resonance diagrams similar to those of the working point. In the following we discuss the means to vary the phase advances and compute the dynamic aperture (DA) for different settings.

\footnotetext{
*Work performed under the auspices of the United States Department of Energy
}

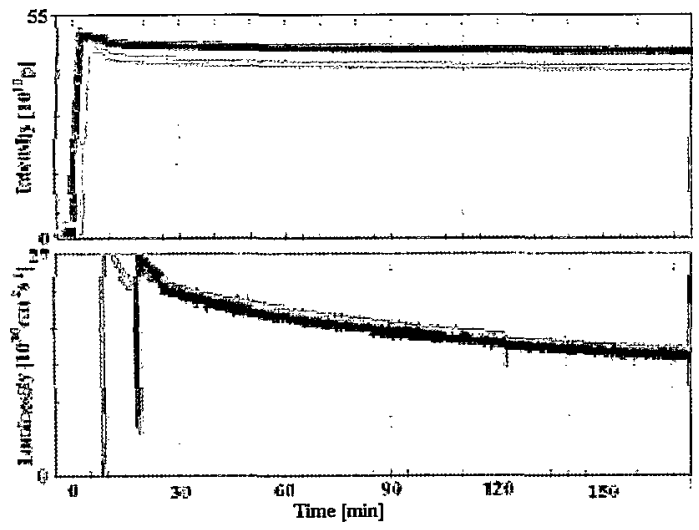

Figure 1: Luminosity decay for a store with 28 bunches. Note that the beam intensity is almost unchanged over the store length.

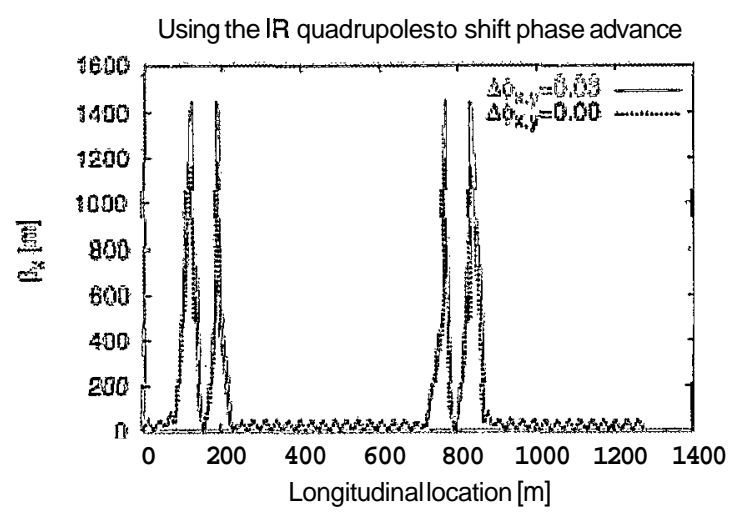

Figure 2: Optics for two phase advance configurationsusing the IR quadrupoles.

\section{MEANS TO VARY $\Delta \phi_{X, Y}$}

We have studied four different ways to vary the phase advances between the two IPs. We separate them in cases that would need new hardware and those that don't.

Do not need new hardware:

1. Using IR quadrupoles: The IR quadrupoles have independent power supplies that could be used to modify the phase advances. However this yields large changes in the betatron functions in the triplets, enhancing the large non-linearities present in these areas (see Fig. 2). 

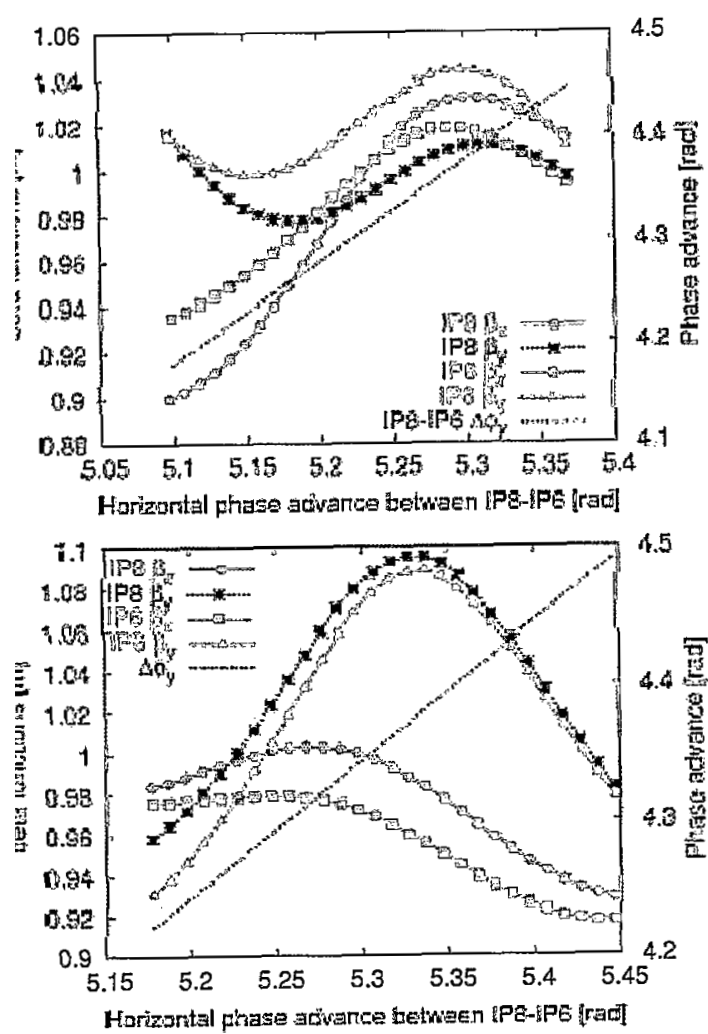

Figure 3: Twiss functions at the IP wersus horzmtal phase alvance for tures $\left\{Q_{2}, Q_{3}\right)=(0.225,0.235)$ (toph and tunes $\left(Q_{3}, Q_{3}\right)=(0.69,0.665)$ (botton).

2. Using the rinjump quadrapoles: These quadrupoles are used to thange the latice or rapidy wite the beam crosses the transition energy, and are not usesl during stores. Thess gutudrupoles are mainly phased at focusing lowntions and therefore the efreb on the vertical phrase advance is very limited.

Need new hardware:

3. Using all are quadrupoles in between the IPs: This technique needs two new independent power supplies, and changes the lattice functions at the IPs, slightly stronger for the RHIC proton working point $(0.69$, 0.685 ) than for the traditional RHIC working point $(0.225,0.235)$ (see Fig. 3).

4. Using 8 independent arc quadrupoles: This is the most precise way to control the phase advances and beta functions since it provides enough degrees of freedom.

We further discuss only cases 3 and 4 , which require new hardware. rnase scall for (U.c<o, U.cou)
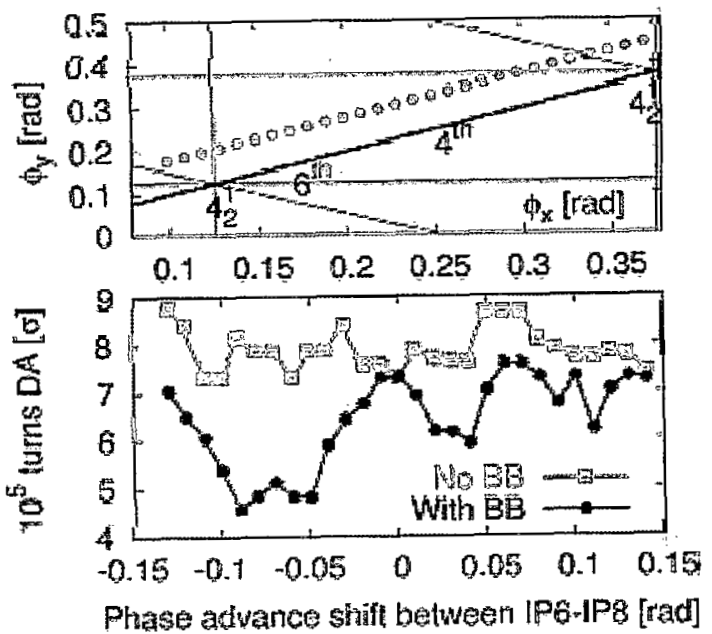$$
\begin{aligned}
& t^{2} \\
& \mathbf{u} \\
& \mathrm{y} \\
& \mathrm{t}
\end{aligned}
$$

Phase scan for $(0.69,0.685)$
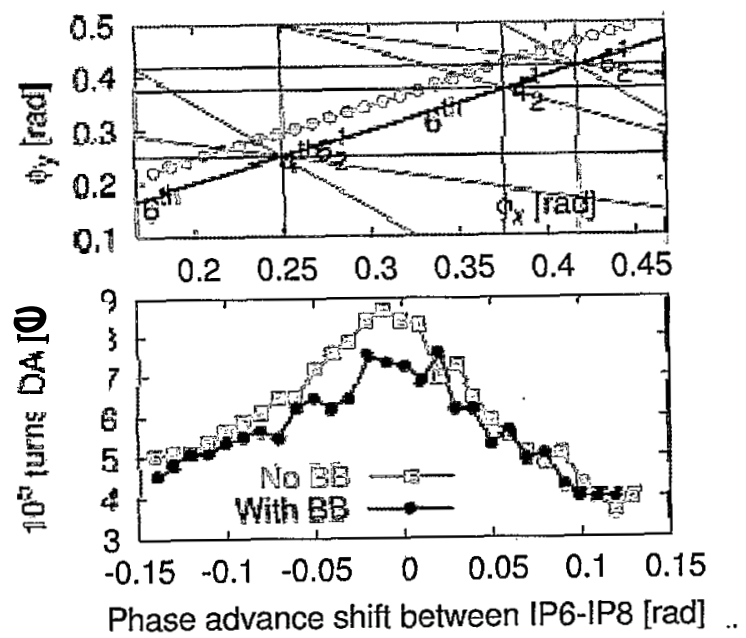

Figure 5: DA for the working point $(0.69,0.685)$ using all arc quadrupoles. The top plot shows the working point in the phase advance diagram.

\section{DA CALCULATIONS}

We compute the DA for cases 3 and 4 using a complete non-linear model of the accelerator [2]. The DA is defined in this work as the minimum unstable transverse amplitude found along five angles of the transverse plane for $10^{5}$ turns. The beam-beam interaction is introduced using the weak-strong approximation. The SixTrack $[3,4]$ tracking code has been used for all the simulations.

The results for case 3 , when using all arc quadrupoles to 


\section{Phase scan for $(0.69,0.685)$}

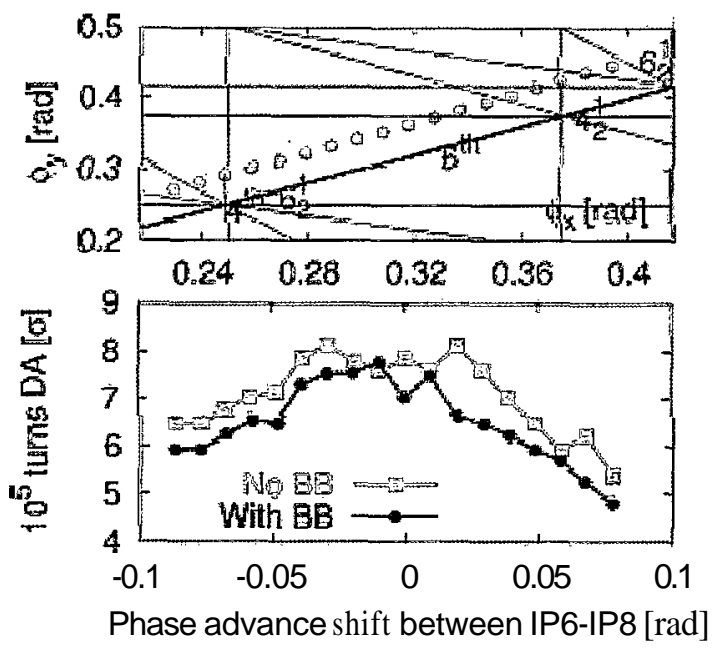

Figure 6: DA for the working point $(0.69,0.685)$ using 8 independentarc quadrupoles. The top plot shows the location on the horizontal and vertical phase advance .

change the phase advances, and the RHIC working point $\left(Q_{x}, Q_{y}\right)=(0.225,0.235)$ are shown in Fig. 4 . The top plot shows the used horizontal and vertical settings in the phase advance diagram together with the resonance lines as described above. The blue lines represent the locations with zero resonance strength and the black lines those with maximum strength for a particular resonance. The bottom plot shows the computed DA for the different settings for two cases: with beam-beam interaction and without beambeam interaction. The phase advances with minimum DA in the beam-beam case correspond to crossings with maximum fourth and sixth order resonance strength. While the maximum DA is found at a fourth order resonance with zero strength. This result shows a large influence of the phase advance on the beam stability in the presence of beam-beam.

The results for case $\mathbf{3}$, using again all arc quadrupoles, and the RHIC proton working point $\left(Q_{x}, Q_{y}\right)=$ $(0.690,0.685)$ are shown in Fig. 5. A different behavior is observed for this working point. Both DAs, with and without beam-beaminteraction, decrease a5 we move away from the central point. The DA is not dominated by the beam-beam interaction.

Initially we assumed that the lattice perturbations were the cause of this behavior and a more refined optics matching was needed. For case 4 , we used 8 arc quadrupoles to match the optics (lattice functions $\beta$ and $\alpha$ for both the horizontal and vertical plane, not the dispersion) in the IR. The results for this case are shown in Fig. 6. The decrease of the DA is still observed, therefore the non-linearities of the lattice have to be enhanced by moving the phase advances. This point is confirmed by computing relevant lattice resonance terms. They are shown in Fig. 7 having a minimum in the center of the graph and thus confirming the hypothe-
SPS tunes $(0.69,0.685)$

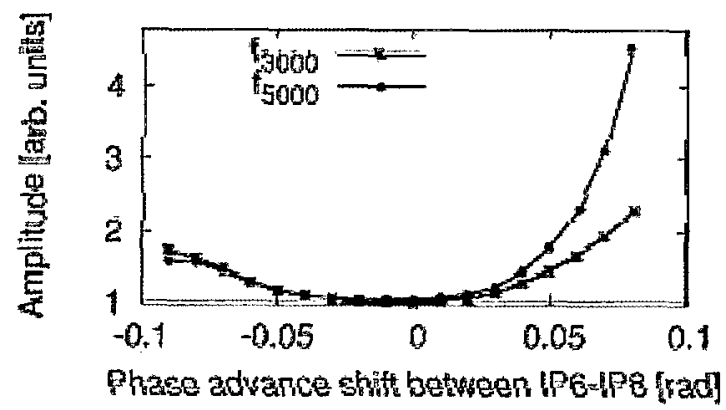

Figure 7: Strengths of two lattice resmances as a function of the hurizontal phase advenet shill between the two IPS,

sis.

\section{CONCLUSIONS}

Four different ways of varying the phase advance between two IPs have been studied to mitigate beam-beam effects during RHIC stores. Configurationsthat do not require the installation of new hardware either distort the lattice functions or are ineffective.

Computations of the dynamic apertures for the working point $(0.225,0.235)$ show that the optimum setting of the phase advances between the IPs is not the initial one. Furthermore, a clear correlation between the resonances of the two kinds (maximizing and vanishing resonances) in the phase diagram and the dynamic aperture has been observed.

At the RHIC proton working point $(0.690,0.685)$, changes in the phase advance between the IPs lead to stronger lattice resonances that shadow possible reductions of the beam-beam resonance strengths. No improvement of the dynamic aperture has been found for this working point.

\section{ACKNOWLEDGEMENTS}

The authors thank S. Tepikian and Y. Luo for help with the RHIC model. Thanks also to'M. Bai and T. Roser for fruitful discussions.

\section{REFERENCES}

[1] R. Tombs, M. Bai, W. Fischer, V. Ptitsyn, T. Satogata and T. Roser, "Quest for a new working point in RHIC", EPAC 2004.

[2] R. Tombs, W. Fischer, A. Jain, Y. Luo and F. Pilat, "Nonlinear modeling of the RHIC interaction regions", EPAC 2004.

[3] F. Schmidt, "SixTrack: Version 3, Single Particle Tracking Code Treating Transverse Motion with Synchrotron Oscillations in a Symplectic Manner, User's Reference Manal" ,CERN/SL/94 56 (AP).

[4] R. Tomás, "SixTrack Running Environment in Godzilla", BNLL C-A/AP/166, 2004. 